\title{
Los impactos distributivos de las reformas institucionales
}

Fernando Toboso*

\begin{abstract}
Resumen
El objetivo aquí perseguido es doble. Por una parte, se pretende mostrar que la afirmación de que los nuevos institucionalistas no prestan atención a los aspectos distributivos puede ser refutada. Para ello se examinarán algunos trabajos de destacados autores en esta tradición analítica. En segundo lugar, el trabajo acomete la revisión y ampliación de un instrumental gráfico muy conocido y nada heterodoxo a fin de realizar un análisis sistemático y muy persuasivo de las principales vías por las que una reforma institucional provoca impactos distributivos, además de influir sobre el volumen total de los costos de transacción que soportan los participantes en cada entorno institucional. Dicho análisis también permite resaltar que las reglas que unos agentes perciben como causantes de los costos de transacción que ellos soportan son vistas por otros como los mecanismos que les pueden permitir, finalmente, obtener mejores resultados distributivos, al menos a corto plazo, incluso aunque hayan de incurrir en los habituales costos de transacción asociados a toda negociación. Aunque estas ideas resultan ciertamente ajenas al proceder investigador de muchos nuevos institucionalistas, no es así en el caso de otros como North, Eggertsson, Libecap, Ostrom e incluso Williamson y Ménard. Evidentemente, esta dimensión distributiva suele ser objeto de gran preocupación por parte de investigadores que trabajan en el marco de otras corrientes de análisis, pero el objetivo del trabajo no consiste en examinar esas otras aportaciones, sino en mostrar que estos aspectos están ganando más y más espacio en el ámbito de la nueva economía institucional.
\end{abstract}

Palabras clave: consecuencias distributivas, reformas institucionales, nuevos institucionalistas, análisis gráfico estilizado, derechos y capacidades de negociación.

Clasificación JEL: D02, D3, D7.

\section{INTRODUCCIÓN}

El objetivo del presente trabajo consiste, en primer lugar, en mostrar que los aspectos distributivos también están siendo tenidos en cuenta por destacados autores adscritos al campo de la nueva economía institucional, habiendo sido

Manuscrito recibido en enero de 2013; aceptado en noviembre de 2013.

* Departamento de Economía Aplicada de la Universidad de Valencia, España, <Fernando.Toboso@uv. es>. El autor agradece los valiosos comentarios de dos dictaminadores anónimos de la revista. 
varios de ellos incluso presidentes de la International Society for the New Institutional Economics (ISNIE). En segundo lugar, el trabajo aporta, mediante la revisión y ampliación de un instrumental gráfico muy conocido y nada heterodoxo, un análisis microeconómico sistemático y muy persuasivo de las principales vías por las que una reforma institucional provoca impactos distributivos muy relevantes sobre unos y otros participantes, además de afectar al volumen total de los costos de transacción que conjuntamente soporten dichos agentes.

Para el logro de estos objetivos, lo que sigue a esta introducción se organiza del siguiente modo. En el siguiente apartado se examinan los trabajos de esos destacados nuevos institucionalistas en los que se presta atención, en mayor o menor medida, a los aspectos distributivos. Tal es el caso de algunas de las obras de autores como North, Ostrom, Greif, Knight, Eggertsson, Libecap, Winiecki, Horn o Weingast. A continuación se muestra el instrumental gráfico a utilizar y la modificación que es necesario hacer en el mismo para que resulte útil a los propósitos aquí perseguidos y, posteriormente, se procede a realizar el análisis gráfico estilizado de los impactos distributivos ocasionados por las reformas institucionales. Dicho análisis revelará cómo las reformas institucionales influyen de manera diferente sobre los derechos de unos u otros participantes y sobre sus oportunidades y capacidades relativas de actuación y negociación. No sólo afectan, pues, a la cantidad total de costos de transacción que conjuntamente soportan dichos participantes. Estas y otras conclusiones se sintetizan en el último apartado.

A fin de evitar cualquier posible mala interpretación de las conclusiones a las que la presente investigación permite llegar, resulta necesario mencionar aquí que en el trabajo no se afirma que esta ampliación de enfoque hacia los aspectos distributivos sea mayoritaria entre los autores que participan en los congresos de la ISNIE y se autocalifican como nuevos institucionalistas. Aunque se ha producido una considerable ampliación en el enfoque respecto a los trabajos publicados durante las décadas de 1970 y 1980, todavía son minoritarios los trabajos en los que la dimensión distributiva está explícitamente presente. Por tanto, haciendo abstracción de las particularidades y las diferencias de planteamiento siempre existentes, es necesario resaltar en esta introducción que dicho enfoque de análisis mayoritario sigue caracterizándose, sin duda, por la especial preocupación que estos autores tienen por el tema de los costos de transacción y su repercusión sobre el mayor o menor grado de eficiencia resultante en cada entorno institucional investigado, tanto en el ámbito del sector privado, los mercados y las empresas como en el del sector público y los procesos políticos. 
No obstante lo anterior, resulta posible afirmar también que ya en la década de 1990 existía entre los nuevos institucionalistas una evidente insatisfacción respecto al tipo de análisis económico elaborado bajo las concepciones neoclásicas tradicionales que, por otra parte, habían inspirado sus propias y pioneras aportaciones de los años 1960 y 1970 en campos como el de la llamada teoría de los derechos de propiedad. ${ }^{1} \mathrm{Al}$ igual que dichas aportaciones, poco tienen que ver con las aproximaciones metodológicas y los posicionamientos normativos que suelen predominar en los trabajos de los viejos institucionalistas. ${ }^{2}$ En ese sentido, en la actualidad son claramente mayoritarios los autores que trabajan bajo la presunción de que las personas disponen de una racionalidad limitada 0 acotada, ${ }^{3}$ no de unas ilimitadas capacidades de procesamiento de la información y de cálculo. De ahí que, en dichos análisis a los agentes no se les suela atribuir la tenencia de una información perfecta o completa ni el planteamiento consista tampoco en asumir que obtener información es costoso y que, por lo tanto, el agente "optimizará" la búsqueda de la misma. Por el contrario, lo habitual es encontrar análisis basados en la presunción de que los agentes pueden actuar de manera oportunista, incumplir sus promesas, revelar información distorsionada e incluso incumplir la legislación.

Williamson (2002a; 2002b) ha sintetizado algunas de esas principales diferencias entre el enfoque de la nueva economía institucional y lo que él mismo denomina la "ortodoxia neoclásica". Diferencias que concreta en tres aspectos esenciales. El primero y principal hace referencia al hecho de que mientras la perspectiva institucional o transaccional permite enfatizar los aspectos de negociación y las posibles ganancias del intercambio que pudieran resultar, entre otros muchos aspectos, la perspectiva neoclásica tradicional conduce a enfocar los problemas microeconómicos desde una perspectiva que busca determinar cuál es la asignación más eficiente de los recursos escasos (precios y producción de

\footnotetext{
1 Sobre estas aportaciones, véase Eggertsson (1990: cap. 8).

2 Ejemplos de trabajos en los que se examinan esas tradicionales diferencias de enfoque entre la nueva y la vieja o pionera economía institucional son Hodgson (1989; 1993; 1998), Rutherford (1994; 1995), Toboso $(1995 ; 1997 ; 2001 ; 2013)$ o Hutchison (1984). Caballero y Kingston (2009) hacen un amplísimo repaso de diversas aportaciones realizadas al estudio del cambio institucional desde diferentes corrientes de análisis institucional.

3 Sobre el supuesto de racionalidad acotada o limitada, véanse Langlois (1990), Williamson (1990), Selten (1990), Knudsen (1993), Kahnerman (1994) o Pagano (2007), además de los clásicos trabajos de Simon (1976; 1978; 1979).
} 
equilibrio son las preocupaciones fundamentales de los analistas). Segundo, y relacionado con lo anterior, en los análisis tradicionales de inspiración neoclásica las empresas se suelen conceptualizar — dice Williamson-como si fueran funciones de producción a maximizar, mientras que la perspectiva transaccional permite enfatizar los aspectos relacionados con la estructura de gobierno de dichas empresas y los entramados de reglas formales y normas informales que constriñen las interacciones de los agentes participantes. Y tercero -señala Williamson-, la perspectiva transaccional propia de los análisis elaborados en el marco de la nueva economía institucional facilita el que podamos incorporar a nuestro análisis las aportaciones que han tenido lugar en otros campos, como el de la teoría de la organización. ${ }^{4}$

Así pues, dependiendo del área de investigación, no resulta difícil encontrar ahora trabajos en los que los nuevos institucionalistas prestan atención, por ejemplo, al grado de credibilidad de los compromisos, a los aspectos de gobernanza, a las normas y valores sociales, a las convicciones y predilecciones ideológicas, a los mecanismos de refuerzo, al capital social, a los comportamientos estratégicos, a la racionalidad limitada, al oportunismo, a la selección adversa, al riesgo moral, a las garantías contractuales, a la incertidumbre, a los costos de supervisión, a los incentivos a la colusión o a las estructuras jerárquicas. ${ }^{5} \mathrm{E}$ incluso, como veremos en el próximo apartado, a los conflictos distributivos, a la fuerza negociadora de unos u otros participantes, a la información asimétrica o a las habilidades de persuasión de cada cuál.

No es casualidad que Elinor Ostrom, recientemente galardonada con el Nobel de Economía, mencione explícitamente la necesidad de ir más allá de las panaceas teóricas para construir "una ciencia claramente interdisciplinar a fin de analizar sistemas complejos formados por múltiples niveles, evitando así la adopción de modelos teóricos simplistas en la búsqueda de verdades predictivas universales (panaceas) para complejos problemas de decisión e interacción colectiva" (Ostrom, 2007a). ${ }^{6}$ Bien conocidos son también sus análisis sobre la importancia que el capital social y otros aspectos reputacionales y relacionales

\footnotetext{
4 Véase también Williamson (2000; 2003).

5 Véanse las colecciones de trabajos publicadas en Ménard (2004), Ménard y Shirley (2005), Svendsen y Svendsen (2008), Toboso y Arias (2006), o los libros de North (2005a), Eggertsson (2005) y Ostrom (2005).

6 Véase también Ostrom (2007b).
} 
tienen en cuanto factores que pueden ayudar a resolver o mitigar problemas de acción colectiva y coordinación social. ${ }^{7}$ No es casualidad tampoco que North (2005b: 21) escribiera que:

“[...] en contraste con teoría económica estándar (neoclásica) que suele estar inspirada en las concepciones de la física mecanicista, la modelización de los procesos de cambio económico ha de inspirarse en la biología evolutiva. Pero a diferencia de lo que ocurre en las explicaciones de la teoría de Darwin en las que los mecanismos de selección no se ven influidos por las creencias acerca de las potenciales consecuencias, la evolución de los asuntos humanos si que está influida por las percepciones de los jugadores acerca de esas posibles consecuencias de las decisiones-elecciones [...] cada cual tratando de lograr sus propios objetivos."

\section{Ejemplos de ANÁlisis en los QUe SE PRESTA ATENCión A LOS ASPECTOS Distributivos}

Explicitadas esas características del enfoque mayoritario, se hace necesario mostrar ahora algunos ejemplos de análisis en los que, además de esas ampliaciones anteriores, también se presta atención a los aspectos distributivos. Como ya se mencionó, el objetivo último de este trabajo consiste en refutar la afirmación de que los nuevos institucionalistas siguen ignorando estos aspectos, para lo cual no es necesario realizar un repaso de todas las aportaciones, sino examinar sólo algunos destacados ejemplos.

El primero a mencionar es Douglass North. Aunque North se suele centrar en analizar cuestiones relacionadas con la eficiencia de unos u otros marcos institucionales, vinculando su diagnóstico a los mayores o menores costos de transacción totales resultantes para los participantes, también ha publicado trabajos que contienen explicitas referencias a los aspectos distributivos o al poder negociador de los participantes. Esos trabajos constituyen pues el primer ejemplo a examinar aquí. Así, en North (2005b: 112) se hace referencia a la "lucha violenta entre grupos que compiten por el control de la política y la economía” que tuvo lugar en todas las nuevas repúblicas latinoamericanas creadas después de la derrota de los españoles y el surgimiento de los movimientos de independencia. Aun cuando muchos países adoptaron una u otra versión adaptada de la Constitución de los Estados Unidos de Norteamérica tras su independencia, las

7 Véanse Ostrom (2005), Ostrom y Ahn (2008), Ostrom y Walker (2005) o Poteete, Janssen y Ostrom (2010). 
consecuencias de dichos marcos institucionales - escribe North - resultaron radicalmente diferentes a lo esperado, dada la herencia colonial de todos estos países. Los sistemas económicos y de comercio de dichos países se orientaron básicamente hacia la extracción de metales preciosos para la Corona española, quien otorgó el monopolio exclusivo de tales actividades a determinados grupos, restringiendo también el comercio a un pequeño número de puertos de entre todos los existentes en América del Sur. El propósito evidente y bien documentado de esta configuración institucional — dice North— fue el de facilitar la extracción y el envío de los metales preciosos a España, no el promover el desarrollo de las personas que vivían allí.

Al no contar con una tradición de autogobierno democrático ni con reglas políticas y de mercado bien definidas y con garantía de cumplimiento ni con una socialmente legitimada distribución de la propiedad de los recursos económicos, la independencia de estos países acabó conduciendo a una violenta batalla entre diversos grupos por la captura del proceso político y el control de los negocios económicos - señala North. Los grupos que salieron victoriosos instauraron regímenes autoritarios a fin de asegurar el orden que les beneficiaba y el fenómeno del "caudillismo" se convirtió en omnipresente. Pero pronto aparecieron también nuevos conflictos entre los inicialmente beneficiados por la Corona y las nuevas élites gobernantes que pronto emergieron y los grupos en los que se apoyaban, quienes no estaban entre ese reducido número de familias terratenientes y miembros de la iglesia a los que la Corona había entregado enormes extensiones de tierra y monopolios locales para la producción y el comercio. El resultado fue, y sigue siendo según North, una inestabilidad política continua y una generalización del fenómeno de la búsqueda de rentas con efectos muy negativos sobre las actividades productivas. La enormemente desigual distribución de la renta y la riqueza generada, la casi inexistente provisión de bienes públicos y la pobreza extrema que asola a una parte considerable de la población de muchos de estos países es en gran parte el resultado de dicha dinámica institucional. North concluye que las explicaciones del subdesarrollo basadas en las dotaciones relativas de capital físico o en la configuración institucional formal no pueden ignorar la relevancia de las instituciones informales y los conflictos que pueden surgir en muchos casos.

Todos estos argumentos de North son, por supuesto, discutibles. Sin embargo, los mismos revelan que algunos de sus análisis presta atención a las cuestiones distributivas, a los conflictos de intereses, a la existencia grupos de personas con 
capacidades diferentes para influir sobre las nuevas reglas del juego político y económico que se crean y reforman, o con diferentes capacidades de negociación bajo las reglas existentes. En North (2005a: 165) este autor escribe también: "Como se señaló anteriormente, la alteración de las reglas económicas implica ganadores y perdedores, y es fundamental estar al tanto de ello [...].” En 1990 este autor ya había declarado explícitamente: "Las instituciones no son creadas necesariamente, ni siquiera habitualmente, para ser socialmente eficientes, más bien, o al menos las reglas formales, son creadas para servir a los intereses de quienes tienen el poder de negociación suficiente para elaborar y aprobar nuevas reglas" (North, 1990: 16). En un sentido similar, otro ex presidente de ISNIE, Eggertsson (1996: 16), declaró explícitamente que la perspectiva de la nueva economía institucional "también ofrece una oportunidad para explicar los mecanismos institucionales que influyen sobre el poder relativo de los trabajadores y empleadores, así como para explorar cómo esas relaciones de poder han surgido y cómo se mantienen [...]". ${ }^{8}$

Knight y North (1997) y Knight (1992) constituyen otros dos clásicos ejemplos. El énfasis puesto por muchos analistas en los beneficios totales que un grupo de personas obtiene de los arreglos institucionales existentes - afirman Knight y North - les lleva a ignorar una dimensión muy relevante de las interacciones humanas en cualquier entorno institucional. Se trata de la dimensión distributiva y el conflicto de intereses que puede aparecer en relación con el status quo institucional existente en cada ámbito y sus posibles vías de reforma. Y ello vale tanto para las instituciones formales como para las informales. Knight (1992: 17) afirma:

Las principales conclusiones a extraer de mi análisis es que la evolución registrada en las instituciones sociales se explica mejor en cuanto subproductos de los conflictos distributivos existentes que por referencia a acuerdos voluntarios Pareto-superiores para el logro de beneficios conjuntos. Con el fin de evitar confusiones innecesarias, quiero subrayar aquí que mi énfasis en la necesidad de hacer referencia a los efectos distributivos esperados como factor explicativo del cambio en las instituciones sociales no implica que las instituciones existentes no ofrezcan también beneficios colectivos en cierta medida.

Otros muchos ejemplos podrían ser mencionados en relación con la aportación de Knight. Por ejemplo, en Knight (1992: 194) este autor menciona que estos

8 Véase también Eggertsson (1995: 48) y Toboso y Compés (2003: 664). 
aspectos distributivos no son sólo factores claves para explicar muchas de las reformas institucionales que finalmente vemos aprobadas en las actuales sociedades democráticas, sino que igualmente también para "explicar la manipulación de las instituciones electorales ocurrida en las asambleas de Roma en el siglo IV A.C.". En la medida en que el derecho al voto y la representación en dichas asambleas se organizaban bajo criterios tribales, los resultados de los procesos electorales podían fácilmente alterarse con sólo modificar los requisitos para poder formar parte de cada estrato social. Así, en el año 312 A.C. cuando Apius Claudius quiso otorgar una mayor influencia a los intereses de los comerciantes de las áreas urbanas, simplemente intentó reformar la ley electoral para permitir que los residentes de los cuatro grandes distritos urbanos se pudieran inscribir, sin embargo, como electores en los distritos o áreas de su elección, independientemente de su lugar de residencia. Varios años más tarde, la ley se cambió de nuevo para obligar a los votantes urbanos a ejercer sus derechos electorales es los distritos urbanos en los que tenían fijada su residencia, permitiendo de nuevo así volver a ser mayoría en sus distritos a quienes trataban de conservar la primacía de los intereses agrarios en la Roma de aquellos años al recuperar por un tiempo el marco institucional que les favorecía — escribe Knight.

El interés de North y otros nuevos institucionalistas por estos aspectos queda puesto también de manifiesto por el hecho de haber invitado a Jack Knight a publicar su impactante tesis doctoral de 1992 (Institutions and Social Conflict) en la serie The Political Economy of Institutions and Decisions, editada por James E. Alt y Douglass C. North, o que Knight y North publicaran "Explaining the Complexity of Institutional Change" en 1997, trabajo en el que ambos ponen énfasis en esos aspectos.

Algunas de las contribuciones de Barry Weingast ${ }^{9}$ se pueden citar también como ejemplos de análisis en los que los aspectos distributivos son tenidos en cuenta, aunque de manera tangencial. Así por ejemplo, en los artículos clásicos y muy citados de Weingast y Marshall (1988) y Weingast (1989), estos autores mencionan que el control sobre el orden del día dentro de su jurisdicción por los comités en el Congreso de Estados Unidos implica que cada comité tiene poder de veto sobre las propuestas que se elevarán para votación al pleno del Congreso. Este control de la agenda permite a los comités orientar el resultado

9 Weingast (1989), North y Weingast (1989), Weingast y Marshall (1988) o Horn (1995) pueden citarse como ejemplos de dichos trabajos. 
de las decisiones hacia las alternativas preferidas por la mayoría de los miembros de cada comité, que cuentan con nombramientos de por vida. Las consideraciones distributivas están presentes pues en dicho análisis. La diversidad de intereses entre los legisladores — escribe Weingast - crea oportunidades para el mutuo beneficio y el intercambio de apoyos entre los miembros de los comités. Pero bajo un sistema de intercambio puntual de favores y apoyos en el pleno de la Cámara, los riesgos derivados del incumplimiento de la palabra dada serían superiores — señalan Weingast y Marshall— que con el actual sistema de comités del Congreso estadounidense. Resulta necesario mencionar aquí, no obstante, que la preocupación principal para estos autores es, por supuesto, determinar si dicho sistema es más eficiente que el otro en el sentido de que genera unos menores costos de transacción para los legisladores en su recurrente tarea de alcanzar acuerdos sobre las medidas legislativas a adoptar, ceteris paribus. La respuesta es afirmativa, según éstos autores, puesto que si los legisladores buscan en último término ser reelegidos en sus propias circunscripciones preferirán dicho sistema frente al tradicional sistema de intercambio puntual de apoyos o votos, porque dicho sistema asegura el cumplimiento de lo pactado en mayor medida que el otro, permitiendo así sacar adelante, con unos menores costos de transacción, las propias propuestas en beneficio de los electores de su circunscripción.

Dado que el apoyo presente otorgado a una iniciativa legislativa es algo cierto, mientras que la promesa de apoyo futuro puede verse incumplida por múltiples razones (entre ellas el cambio en las circunstancias que dieron lugar al pacto o el cambio de opinión resultante del paso del tiempo), parece obvio que los legisladores preferirán aquel sistema que mejor asegure el cumplimiento de lo pactado. Según Weingast, ni los factores de reputación ni el que la interacción sea repetida impiden que en determinadas circunstancias los acuerdos puedan no cumplirse. La diversidad de intereses existente entre los legisladores facilita el logro de acuerdos en mutuo beneficio de los respectivos residentes, pero el sistema tradicional de intercambio puntual de apoyos o votos genera mucha más incertidumbre sobre el resultado final y, por lo tanto, unos mayores costos de transacción que el sistema de comités mencionado, dada la permanente posibilidad de incumplimiento o la exigencia de renegociación como consecuencia de los cambios de contexto o de opinión mencionados. El convencimiento progresivo de que ello era así condujo en su momento a la aprobación de las modificaciones reglamentarias que supusieron la implantación del mismo sin apenas oposición. 
Estos autores elaboran un modelo con un sistema ideal de comités y argumentan que la evidencia empírica obtenida del funcionamiento del Congreso estadounidense no refuta dicho modelo. En él, los comités legislativos están formados por determinados escaños. Cada escaño pertenece a un congresista individual, quien ostenta un derecho de propiedad sobre el escaño. La asignación es histórica, basada en la antigüedad (seniority system) y da derecho a permanecer en ese puesto hasta que el congresista lo desee. Cada comité tiene asignado un conjunto de temas sobre los que ejerce el derecho exclusivo a proponer actuaciones y reformas para ser votadas en el Congreso. Cuando un puesto queda vacante, éste se ocupa por un procedimiento técnico consistente en ver cuál es el congresista más antiguo que lo solicitó en un orden anterior en su declaración escrita de preferencias de pertenencia a comités. El control de la agenda, esto es, qué propuestas se presentarán a votación, y cuándo y cómo, en el Congreso otorga a los comités un derecho de veto sobre las propuestas que otros congresistas puedan hacer a dicho comité y sesga el proceso hacia la presentación de aquellas propuestas más deseadas por los miembros del comité. No es por ello extraño ver como los congresistas provenientes de distritos rurales solicitan pertenecer en primer lugar a los comités sobre temas agrarios y no al comité de vivienda ni al comité de la marina mercante, por ejemplo. La estabilidad de las alianzas y acuerdos dentro de un comité o entre miembros de distintos comités se ve reforzada por el sistema de propiedad de los puestos prevaleciente. ${ }^{10}$ Como veremos en el apartado siguiente, la institucionalización de dicho sistema de intercambios y apoyos no es, por lo tanto, neutral ni en términos de resultados globales ni en cuanto a la distribución de los beneficios resultantes de las actuaciones legislativas y presupuestarias finalmente aprobadas en el Congreso.

Todos estos trabajos son sólo ejemplos de análisis elaborados por destacados nuevos institucionalistas. Pero podrían mencionarse otros. Libecap (1989a; 1989b), Winiecki (1994; 1996; 1998), Bardhan (2000; 2001; 2004, 2005), Greif (2005; 2008), Nye (1997) o Mokyr y Nye (2007) podrían ser algunos de ellos. Incluso en el ámbito de la organización industrial-empresarial cabe encontrar algunos ejemplos de análisis de destacados nuevos institucionalistas en los que los aspectos distributivos, la fuerza negociadora o el grado de control jerár-

\footnotetext{
${ }^{10}$ Una comparación de esta organización frente a la organización del trabajo legislativo en el Congreso español de los diputados puede verse en Caballero (2006; 2011).
} 
quico ejercido aparecen como aspectos centrales del análisis. Así, Williamson (1996a; 1996b; 1996c; 1997) o dos trabajos de quien fue el tercer presidente de la ISNIE, Ménard (1997; 2004), constituyen otros ejemplos. Ambos autores hacen referencia incluso a las "influencias de poder" entre personas que surgen de las relaciones jerárquicas existentes en el seno de las empresas, estructuras institucionales necesarias para asegurar el control sobre los activos.

Las conceptualizaciones y métodos habitualmente utilizados por los nuevos institucionalistas se han ampliado tanto durante las últimas décadas que no es extraño encontrar trabajos de autodenominados nuevos institucionalistas en los que se hace referencia a situaciones en las que, por ejemplo, algunos grupos de personas pueden oponerse a una reforma tenida por eficiente en la medida en que podría contribuir a una reducción de los costos de transacción si con la misma estiman que se verán afectados negativamente en términos distributivos. ${ }^{11}$ En este sentido, Horn (1995:16) afirma lo siguiente: "si los compromisos de los legisladores a promulgar, así como los beneficios otorgados a sus electores, no están seguros cuando las legislaturas posteriores vienen, pueden tener un incentivo para proteger los beneficios, incluso por tratar de implementar ineficientes mecanismos institucionales que aumentan los costos de transacción de revertir esas políticas". Es importante mencionar que el libro de Horn fue publicado en la colección de libros editados por James E. Alt y Douglass C. North que conforman la serie The Political Economy of Institutions and Decisions.

Esta preocupación por los aspectos distributivos es evidente también entre los nuevos institucionalistas que han realizado contribuciones al análisis de los procesos de reforma institucional habidos en los países de Europa del Este. Como el objetivo de este trabajo no es el de elaborar ningún survey, ${ }^{12}$ bastará con hacer mención a algunos destacados trabajos de Winiecki, varios de ellos presentados en los congresos de la ISNIE. Winiecki (1998; 1996; 1994; 1993; 1991) pueden mencionarse como ejemplos porque junto a sus razonamientos en términos de eficiencia y de costos de transacción, este autor presta también atención a los aspectos distributivos asociados al problema bajo estudio.

${ }^{11}$ Veánse Libecap (1989a; 1989b), Greif (2005), Winiecki (1996) y Bardhan (2000; 2001).

12 Diversos trabajos pueden encontrarse en los últimos volúmenes del Journal of Institutional and Theorétical Economics, en particular el volumen 156, número 1, de marzo del 2000 dedicado integramente a publicar los trabajos presentados en el XVIII Seminario Internacional sobre la Nueva Economía Institucional "Big-Bang Transformations of Economic Systems as a Challenge to New Institutional Economis". 
En Winiecki (1986) se explica cuál ha sido el legado, en materia de instituciones informales, que los sistemas de planificación centralizada han aportado al proceso de transición, mientras que en Winiecki (1998) este autor destaca la importancia que los marcos institucionales informales tienen para el éxito de cualquier reforma legal orientada a implantar economías de mercado de estilo occidental en los antiguos países de economía planificada. En la medida en que los conjuntos de normas, valores, rutinas y hábitos aprendidos y ejercidos durante décadas en el marco de los sistemas comunistas resultan claramente distintos a los valores y hábitos requeridos para el funcionamiento ordenado de las economías de mercado, y dada la mayor dificultad de adaptación de dichas normas y hábitos sociales al haber sido fuertemente interiorizados en las estructuras mentales de la gente, cabe esperar — dice Winiecki- que durante el periodo de transición existan en estos países unos elevados costos de transacción, por comparación con la situación existente en economías de similar atraso económico pero que disponen de las instituciones formales e informales propias de las sociedades democráticas con economías de mercado. No deja de ser este un razonamiento hipotético-deductivo difícil de contrastar, pero Winiecki aporta argumentos de peso para apoyar su afirmación.

Esos elevados costos de transacción se deben en gran medida, según el autor, a factores relacionados con la existencia de determinadas instituciones informales y al impacto que las mismas ejercen sobre la eficacia y cumplimiento de los otros marcos legales en vigor. En primer lugar, en la medida en que la elevada discrecionalidad en la aplicación de la legislación existente en los anteriores sistemas comunistas siguió vigente, dicha práctica o norma social (institución informal) condujo a la elaboración de determinadas normativas legales con redacciones deliberadamente poco precisas. Hacer compatible la consideración de potenciales situaciones particulares con los principios y reglas generales no sólo ha restado eficacia reguladora a dichas normativas, sino que ha hecho incluso a veces inoperativos algunos principios generales - escribe Winiecki. Las modificaciones sucesivas de dichos textos legales a efectos de darles coherencia y, al mismo tiempo, preservar un cierto grado de discrecionalidad dio lugar en muchas ocasiones a una frenética actividad de reforma legislativa. Winiecki (1998: 5) comenta a título de ejemplo como en Hungría durante el periodo 1994-1998 la normativa fiscal (contenida en el tax code) fue modificada 91 veces. El impreciso y cambiante marco legal existente incrementó durante todos esos años los costos de transacción de todas las actividades sujetas a tal 
regulación. Conocer las nuevas normativas, familiarizarse con ellas y estudiar las alternativas disponibles requiere tiempo, esfuerzos y gastos, que serán mayores si dichas normativas cambian frecuentemente. Al igual que los agentes económicos, también los jueces, abogados, concejales, periodistas, etcétera, se ven afectados por esta situación. Obviamente, el cambio de marco legal puede acarrear también pérdidas estrictamente económicas como consecuencia de decisiones que resultan poco acertadas para la mayor parte de los participantes dado el nuevo contexto.

En segundo lugar —escribe Winiecki-, los valores y hábitos sociales prevalecientes en el antiguo y despótico régimen directa o indirectamente primaban los comportamientos estrictamente oportunistas, las sustracciones, las trampas, el fraude, el absentismo, el amiguismo y demás. La ética del esfuerzo y el trabajo estaba tan seriamente dañada, según el autor, que estos valores y prácticas tenderán a perdurar en el tiempo, más allá incluso de los periodos de transición, haciendo de nuevo que los costos de transacción existentes resulten mucho más elevados de lo que sería el caso en países democráticos de economía de mercado que se vieran inmersos en fuertes procesos de reforma legal pero donde la ética del esfuerzo y el trabajo y el respeto a las normas (en cuanto instituciones informales) estuvieran ampliamente difundidas.

En Winiecki (1996), utilizando como referencia las obras de North y Olson entre otras, este autor muestra cómo las reformas institucionales privatizadoras e introductoras de las reglas del mercado representaron en estos países una modificación explícita de las reglas del juego económico, ${ }^{13}$ afectando así a los costos de transacción existentes pero también ocasionando enormes impactos distributivos. Estos previsibles impactos distributivos constituyen para Winiecki uno de los principales factores explicativos de por qué determinados grupos se opusieron a dichas reformas económicas. En la medida en que el poder y el estatus jerárquico adquirido en el antiguo sistema de planificación y dirección burocrática de la economía solía ir asociado a mayores ingresos, rentas y otros privilegios económicos, la previsible pérdida de poder y estatus, derivada de dichas reformas, es previsible que acarree una pérdida igualmente previsible de ingresos y de otros privilegios económicos. Ello permite — dice Winiecki-

${ }^{13}$ Las reglas básicas del juego político democrático y la competencia entre las élites políticas fueron las primeras en ser modificadas al aprobarse las sucesivas constituciones y las posteriores disposiciones legales que desarrollan y concretan dichos principios y normas constitucionales. 
centrar el análisis en estas consecuencias económicas últimas, considerando dichas posiciones de poder como algo instrumental.

¿Qué grupos manifiestaron, pues, una mayor resistencia a dichas reformas liberalizadoras y privatizadoras? Dejando aparte a los grupos de trabajadores y sus organizaciones sindicales pertenecientes a sectores o regiones donde el previsible o ya real aumento del paro resultaba más evidente, quienes adoptaron una posición de mayor resistencia a dichas reformas fueron fundamentalmente, según Winiecki, los antiguos miembros del aparato del Partido Comunista (PC) que ocupaban puestos de control en los distintos municipios, ciudades y comités regionales, comarcales, etcétera, así como los antiguos burócratas-gestores de las empresas. Y ello debido a que son dichos grupos los que más esperaban perder las posiciones de poder de que disfrutaban en el anterior marco institucional y, consiguientemente, las rentas y otros privilegios económicos asociados a las mismas. Con la privatización y las nuevas reglas del mercado, muchos de ellos pasaron a engrosar las cifras de desempleados.

¿Qué ventajas pecuniarias obtenían los miembros del aparato del PC y los gestores económicos que no iban a poder ser mantenidas en el nuevo marco institucional que las reformas estaban introduciendo? En su análisis institucional Winiecki destaca fundamentalmente dos. En primer lugar, los miembros del aparato tenían en su mano el proponer-decidir qué personas iban a ocupar los distintos puestos de dirección y gestión en las empresas y otros entes estatales. Y lo hacían fundamentalmente a partir de criterios de lealtad y vínculos familiares. Diversos conocidos y familiares, incluidos esposa/o e hijos, alcanzaban así puestos de responsabilidad, ingresos explícitos y otras contraprestaciones y beneficios económicos indirectos a los que no hubieran tenido acceso de no ser por dichos nombramientos. O encontraban empleo posteriormente al ser recomendados ante dichos directivos como candidatos para ser contratados en las más diversas tareas. Este derecho a designar cargos se conocía como el principio de la nomenclatura. La lealtad de cada cual con respecto a la persona o personas de las que uno se siente laboralmente dependiente, y al mismo tiempo agradecido, así como el cumplimiento formal de las órdenes recibidas en materia de dirección y gestión, condujo en innumerables casos a la falsificación de los informes de situación y las cuentas presentadas que se trasladaban hacia arriba en prueba de cumplimiento de los planes acordados, para satisfacción formal de unos y otros.

Una segunda vía de apropiación de ingresos o beneficios económicos por parte de los dirigentes del aparato del PC, tanto en la antigua Unión de Repúbli- 
cas Socialistas Soviéticas (URSs) como en los países de Europa del Este, que las reformas ponían en peligro es el también conocido mecanismo de los pagos en especie. Según Winiecki, era algo habitual que los gestores de empresas públicas canalizaran tanto hacia sus padrinos como hacia otros posibles impulsores de su carrera política bienes y servicios de la propia empresa con fuertes descuentos o a un precio muy inferior al que se podían vender en el mercado negro, o incluso de manera gratuita como, por ejemplo, cuando simplemente se envían trabajadores para construir o ampliar un chalet privado o para reparar la carpintería de una vivienda sin hacer constar dicha actividad en los servicios prestados por la empresa. Winiecki (1996:68) afirma en este sentido: "la escasa importancia atribuida a las consideraciones de eficiencia en la actividad de la empresa permite a los gerentes absorber, sin tener que dar cuenta alguna, el coste de estas contraprestaciones [...]. Ambas vías de extracción de renta son posibles gracias al confuso sistema de derechos de propiedad existente en las economías de tipo soviético". Es obvio que dichos pagos en especie también se concedían habitualmente entre gestores de distintas empresas. No resultaba extraño observar tampoco como muchos dirigentes del aparato pugnaban por pasar a ocupar puestos de dirección en las empresas estatales —escribe Winiecki. ${ }^{14}$

Con la sustitución del antiguo marco institucional y la descentralización de la toma de decisiones que la privatización implicaba, estas posibilidades de obtención de rentas y beneficios económicos se reducía drásticamente, y los esfuerzos dirigidos a mejorar la gestión y ahorrar costos de todo tipo aumentaban también en la medida en que aumentaba la competencia en todo el sistema y la financiación externa dejaba de ser un fondo perdido, pasando a tener un costo financiero.

Así pues, no es de extrañar que la resistencia a las reformas fuera grande entre los miembros de estos colectivos, y que las causas del fracaso de muchas de las primeras iniciativas legislativas puestas en marcha durante los años 1990 haya que buscarlas en las acciones y estrategias llevadas a cabo por estos grupos. Incluso en aquellos casos en que dichas reformas se aprueban legislativamente, su puesta en marcha quedaba en manos de esos miembros del aparato y gestores económicos, quienes podían hacerlas fracasar por métodos indirectos.

${ }^{14}$ Winiecki (1986: 70) comenta como en Polonia, al igual que en otros países de Europa del Este, los grupos antes mencionados disfrutaban de un cupón (asygnata) que les permitía adquirir coches para uso privado a menos de la mitad del precio de venta de los mismos. 
Ha de resultar obvio, tras lo visto hasta aquí, que destacados autores que dicen trabajar en la tradición de la nueva economía institucional sí prestan atención a los aspectos distributivos en algunas de sus contribuciones. Para estos autores es evidente que los arreglos institucionales también tienen un impacto significativo sobre quién obtiene qué y cuánto en cualquier ámbito de decisión. En lo que a la acción del equipo se refiere, también es evidente para estos nuevos institucionalistas que las reglas formales e informales por las que se organizan dichos esfuerzos colectivos influyen sobre los esfuerzos y costos soportados por cada participante en ese empeño común. ${ }^{15}$

En este mismo sentido, resulta algo aceptado entre estos autores que aunque los costos de transacción totales resultasen disminuidos por una determinada reforma institucional, ello no garantiza que no haya participantes que resulten distributivamente afectados en un sentido negativo, por lo que cabe esperar que las mejoras de eficiencia sean más defendidas por aquellos que esperan salir ganando con las mismas, en uno u otro aspecto, que por los potencialmente perjudicados, quienes es previsible que traten de oponerse o de reorientar las mismas con mayor o menor determinación dependiendo, entre otros factores, de los conocidos costos asociados a la acción colectiva.

\section{LA UTILIDAd del INSTRUMENTAL DE LA CAJA DE EdgeWorth-BoWley UNA VEZ MODIFICADO CONVENIENTEMENTE}

Los comentarios y citas anteriores revelan que efectivamente ya no es posible afirmar que los nuevos institucionalistas siguen sin prestar atención a los aspectos distributivos. Que en el marco de otras corrientes de análisis institucional, o entre investigadores adscritos a una u otra corriente de análisis político, se presta especial atención a estos aspectos distributivos es algo evidente, pero no es objetivo del presente trabajo examinar esas otras aportaciones. Para completar los objetivos de la presente investigación se hace necesario avanzar un paso más a efectos de mostrar que estas consideraciones distributivas relacionadas con la existencia de unos u otros marcos institucionales, o con su reforma, pueden ser articuladas mediante un análisis microeconómico nada heterodoxo que ofrece un elevado poder de persuasión.

15 Otros trabajos de nuevos institucionalistas en esta línea pueden encontrarse en Harris, Hunter y Lewis (1995), los trabajos publicados en Alston, Eggertsson y North (1996). 
Para ello es necesario realizar una pequeña modificación en el ya clásico instrumental gráfico de la caja de Edgeworth-Bowley, tan conocido por los economistas. Aunque diseñado para enfatizar los beneficios derivados del intercambio voluntario, este instrumental puede ser adaptado para revelar de manera muy persuasiva la dimensión distributiva siempre presente en esas transacciones bajo unos u otros marcos institucionales, que también pueden ser reformados. En lugar de considerar un potencial intercambio de dos bienes privados (bienes, servicios y/o dinero) bajo unas reglas de juego estables, la caja ha de ser modificada para que permita incorporar una actividad que genera efectos externos y para que deje abierta la posibilidad de un cambio en el entorno institucionallegal en el que interactúan los participantes. Esto significa que la tradicional caja de Edgeworth-Bowley se ha de diseñar abierta en la parte superior, esto es sin techo, manteniéndose todas las demás conceptualizaciones y presunciones analítico-metodológicas.

Fue Eggertsson (1990), presidente de la ISNIE tras Ménard y los Nobel de Economía Coase, North y Williamson, quien de manera pionera publicó, hasta donde alcanza nuestra información, una caja de Edgeworth-Bowley sin techo. En su libro Eggertsson hace mención a una ponencia para congreso elaborada por Haddok y Spiegel. Es cierto que Eggertsson no utiliza dicha caja reformada para el mismo fin aquí pretendido, sino para enfatizar que los beneficios potenciales del intercambio de mercado voluntario podrían no hacerse efectivos si los costos de transacción fueran tan elevados como para hacer inviable el mismo. En tales casos - afirma Eggertsson- la eficiencia de esas interacciones podría ser mayor si el marco institucional se reformara en la dirección de reducir esas trabas y costos de transacción asociados a las mismas, incentivándose así un mayor número de intercambios de mercado. Y el autor pone ejemplos. Por ejemplo, escribe, "mediante la introducción de cuotas de pesca individuales y transferibles en los caladeros". ${ }^{16}$ Es evidente que el autor adopta en su libro el enfoque predominante durante aquellos años, y aún ahora, en la tradición de la nueva economía institucional, focalizando su esfuerzo analítico-investigador en cómo los marcos institucionales influyen sobre los costos de transacción, la eficiencia y el crecimiento económico.

\footnotetext{
${ }^{16}$ Aunque el propósito de Eggertsson en dichas páginas no se enfoca en los aspectos distributivos, en la página 109 escuetamente menciona lo siguiente: "la asignación de derechos de propiedad a un individuo genera una especie de efecto riqueza que influye sobre sus propias valoraciones." (Traducción del texto original en inglés).
} 


\section{GRÁfICA $1^{*}$ \\ Marco institucional, costos de transacción \\ $y$ aspectos distributivos}

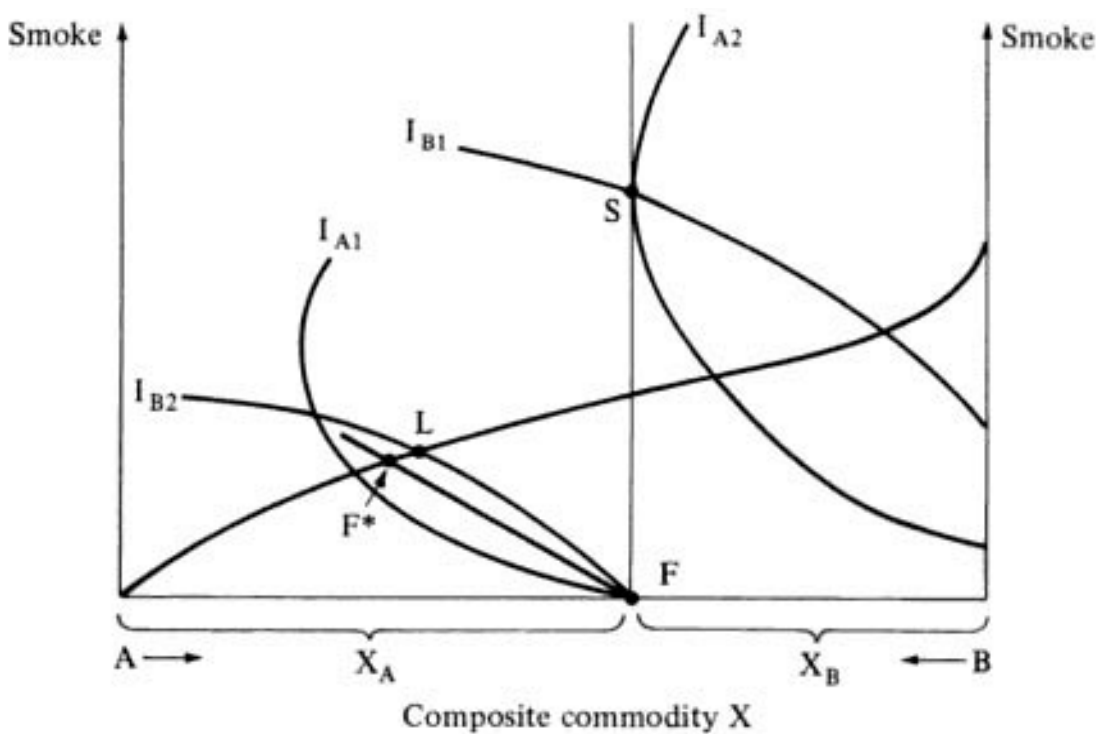

Notas: * Smoke: humo en la sala. Price of smoke: precio del intercambio para lograr más o menos humo en la sala.Composite commodity: cualquier bien privado intercambiable o cesta de bienes. I: las habituales curvas de indiferencia en el análisis de Edgeworth-Bowley.

Fuente: escaneado directamente de Eggertsson (1990: 106), quien refiere tomarlo de una ponencia de Haddock y Spiegel.

Aunque la preocupación analítica aquí es otra, resulta conveniente sintetizar primero el análisis gráfico realizado por Eggertsson en dicha caja reformada a efectos de resaltar la innovación que el presente trabajo supone. En la gráfica 1, expresada en inglés por estar escaneada de Eggertsson (1990: 106), se representa dicha caja de Edgeworth-Bowley reformada. En ella aparecen representados dos agentes que interactúan en un espacio que comparten. Aparece representado también un bien privado intercambiable, o cesta de bienes si se quiere, del que ambos disponen en la cantidad indicada $\left(X_{A}\right.$ para la persona $A$, y $X_{B}$ para la persona B) y también una actividad que genera efectos externos negativos para uno de los participantes, pues uno de ellos es fumador y el otro no. Dicho nivel de humo se mide en el eje vertical.

Aunque en dicha gráfica Eggertsson no les pone un nombre explícito, la misma contiene también dos marcos legales-institucionales alternativos a efectos 
de poder realizar el habitual análisis de estática comparativa, ceteris paribus. Como detallaremos posteriormente en la gráfica 2, uno de esos marcos permite fumar (parte derecha de la gráfica por las razones que explicaremos después), el otro marco institucional prohíbe fumar (lado izquierdo). El aprovechamiento de las ventajas mutuas del intercambio voluntario para ambos agentes —escribe Eggertsson- requeriría en términos gráficos que los participantes pasarán de $\mathrm{S}$ a $\mathrm{S}^{*}$ o bien de $\mathrm{F}$ a $\mathrm{F}^{*}$, dependiendo de la asignación inicial de derechos de decisión sobre la generación de humo en la sala. Asignación que dependerá del marco legal en vigor, como ahora veremos. Si los costos de transacción derivados de esa negociación son bajos, ello será posible. Si son altos puede que no les compense a alguno de los participantes o a ambos, afirma Eggertsson.

Pero, como acabo de mencionar, no son los costos de transacción, la eficiencia y las ganancias del intercambio, dada la situación de partida, los aspectos que se quieren resaltar en este último apartado del trabajo. ${ }^{17}$ Por el contrario, lo que se pretende es revelar cuán importantes y omnipresentes suelen ser los aspectos y consideraciones distributivas en esas mismas situaciones, donde los intercambios voluntarios aparecen como una opción. Y también que esos resultados distributivos dependen en gran parte de los marcos institucionales en vigor, ceteris paribus.

Dichos marcos institucionales no son distributivamente neutrales, porque los mismos influyen sobre la asignación inicial de derechos y capacidades de decisión y negociación de los participantes. Y esto es siempre así, independientemente de la cantidad de los costos de transacción que resulte de una u otra configuración institucional reguladora de la interacción individual o de la negociación para la toma de decisiones colectivas o políticas. La alteración de dichas estructuras institucionales y las reglas del juego que ellas definen genera consecuencias no sólo sobre los costos de transacción y producción total soportados por los participantes en su conjunto (grado de eficiencia global), sino también sobre el reparto de las ganancias derivadas de dichas reformas, ganancias medidas en términos de los actuales y futuros niveles de renta y riqueza que cada cual logrará, ceteris paribus. ${ }^{18}$

\footnotetext{
${ }^{17}$ Sobre estos aspectos véase Eggertsson (1990: 105-7).

18 A efectos de concentrar el análisis en los aspectos que aquí se quieren resaltar, evidentemente otros muchos aspectos institutionales y no institutionales no son tenidos en cuenta. Este es el caso, por ejemplo, de aquellos que hacen referencia a la posibilidad de que algunos participantes pueden tener el derecho a actuar como jugadores con poder de veto. Puesto que el análisis estilizado que nuestro análisis gráfico
} 


\section{CAMBIO INSTITUCIONAL E IMPACTOS DISTRIBUTIVOS: UN ANÁLISIS GRÁFICO}

Para enfatizar estos aspectos distributivos, la gráfica 2 resulta de gran utilidad. La misma representa también una situación muy estilizada y simplificada, como ocurría en la gráfica anterior. En pocas palabras, los principales aspectos de esa nueva situación son los siguientes. En la gráfica 2 se representan las mismas dos personas $(\mathrm{A}$ y $\mathrm{B})$ de la gráfica 1, a las que se supone preocupadas únicamente por sus propios intereses. Ambas han de trabajar en una misma habitación con deficiente ventilación y sin nadie más alrededor. Sólo se toma en consideración para el análisis un marco institucional formal muy simplificado y constituido únicamente por una sola regla legal. Ambos participantes poseen una cantidad de un bien privado intercambiable, o cesta de bienes, tal como se indica en la gráfica a modo de ejemplo. Esa situación estilizada contiene también un efecto externo (el nivel de humo que se genera en la habitación compartida) que afecta negativamente al bienestar del no fumador $(B)$ y que es generado por la persona fumadora $(A)$ cuando subjetivamente calma su adicción al tabaco.

La gráfica 2 también contiene los mismos dos marcos legales-institucionales alternativos que ahora llamaremos explícitamente $\mathrm{MI}_{1}$ y $\mathrm{MI}_{2}$, tal como se muestra en dicha gráfica. El marco institucional denominado $\mathrm{MI}_{1}$ (regla legal: permitido fumar) implica considerar el lado derecho de la caja pues dicha regla legal, como después detallaremos, otorga a la persona fumadora la capacidad de decidir cuál va a ser la situación inicial de partida (nivel inicial de humo en la sala), así como una mayor fuerza negociadora para influir en los términos del posible intercambio posterior. Pasar a considerar la otra posible situación institucional denominada como $\mathrm{MI}_{2}$ (regla legal: prohibido fumar) exige examinar lo situado en el lado izquierdo de la caja a partir de la línea vertical que marca la distribución inicial del bien privado que hemos supuesto para el análisis porque, como ahora veremos, en ese caso es la persona no fumadora quien se hace con el derecho a decidir cuál va a ser la situación inicial de humo, con lo que el nuevo marco legal le otorga una mayor fuerza negociadora.

permite es además un análisis de estática comparativa, todos los aspectos relacionados con las causas y los procesos que conducen a la reforma institucional tampoco son considerados. Sobre actores con poder de veto y sobre otras particularidades relacionadas con los procesos políticos anidados en los que normalmente estas decisiones colectivas tienen lugar puede verse Tsebelis (1990; 2002). 
Los habituales mapas de curvas de indiferencia de cada agente se representan como $\mathrm{I}_{\mathrm{A}}$ e $\mathrm{I}_{\mathrm{B}}$. Como es conocido, cada curva de indiferencia pretende representar las combinaciones alternativas del bien $X$ y del nivel de humo (cigarrillos fumados por la persona fumadora) que harían que cada participante se sintiera subjetivamente igual de satisfecho. Por ello dichas curvas deben dibujarse de la forma tradicional y seguir teniendo orientaciones opuestas.

\section{GrÁFICA 2}

\section{Análisis gráfico de los impactos distributivos del cambio institucional}

$\left[\ldots \mathrm{MI}_{2}\right.$ : prohibido fumar $\left.\quad \ldots\right]\left[\ldots \mathrm{MI}_{1}\right.$ : permitido fumar ...]

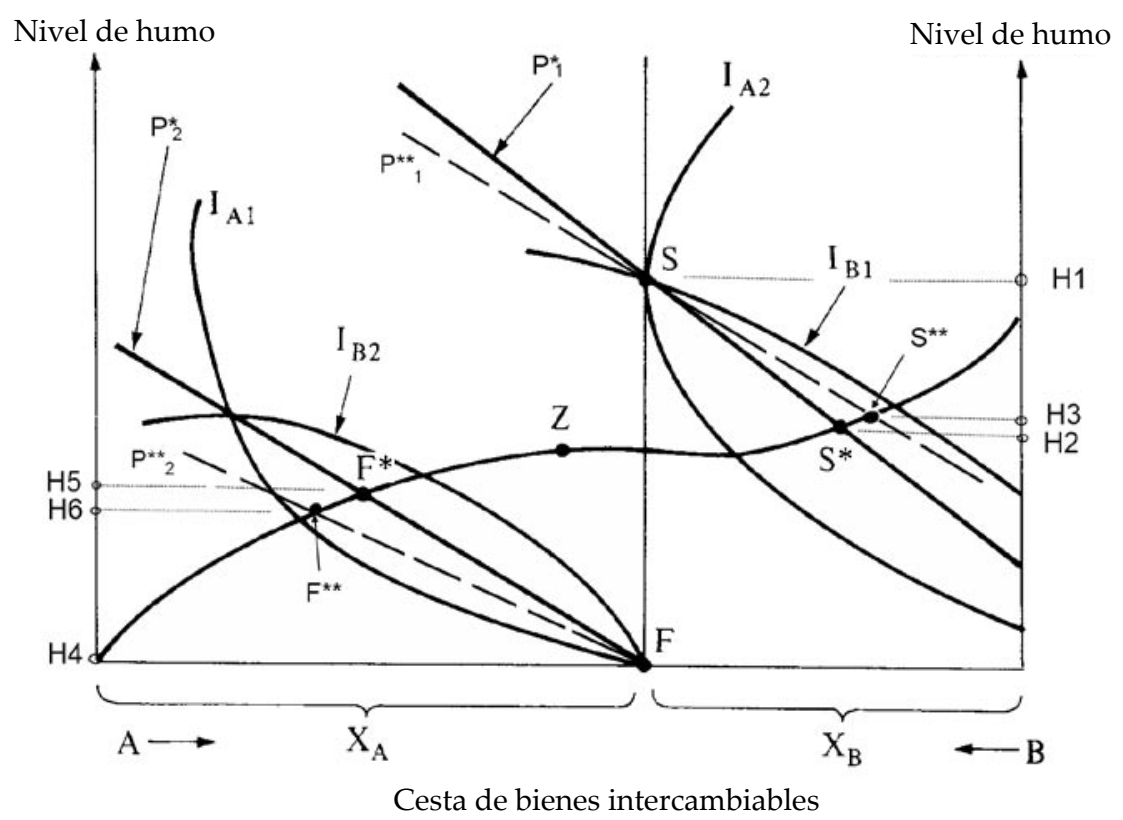

Fuente: elaboración propia a partir de Eggertsson (1990: 106).

En este ejemplo estilizado, y bajo la habitual cláusula del ceteris paribus, si la legislación permite fumar $\left(\mathrm{MI}_{1}\right)$ es la persona fumadora quien posee el derecho de decidir inicialmente la cantidad de humo en la sala común. Esto significa que, en principio, podría fumar tanto como quisiera si no cuenta con una restricción presupuestaria relevante dado el pequeño gasto implicado. Y la otra persona no fumadora experimentaría un ambiente de trabajo lleno de humo. Utilizando 
los conceptos habituales del análisis gráfico de la caja de Edgeworth-Bowley, supongamos que ambos participantes tienen unos mapas de curvas de indiferencia potenciales más o menos estándar, tales como las de la gráfica 2, por ejemplo. Podrían plantearse otras situaciones diferentes, por supuesto. Dadas las conceptualizaciones y presunciones del análisis, si la distribución inicial de $X$ fuera la que se indica en dicha gráfica $\left(X_{A}, X_{B}\right)$, el marco institucional vigente $\mathrm{MI}_{1}$ podría conducir inicialmente (si la persona $\mathrm{A}$ sólo se preocupa por sí misma y es un gran fumador, ceteris paribus) al punto $\mathrm{S}$. Ello significaría que el fumador se colocaría en la curva de indiferencia más alta $\left(\mathrm{IA}_{2}\right)$ que él puede alcanzar en la situación estilizada planteada. La persona no fumadora $\mathrm{B}$ se enfrentaría así a una situación muy diferente en cuanto a su bienestar o utilidad, pues se encontraría con una habitación con altos niveles de humo. Ello habría que representarlo ubicando a dicha persona sobre la curva de indiferencia más baja posible en dicho diagrama $\left(\mathrm{I}_{\mathrm{B} 1}\right)$, dadas las otras presunciones hechas en este súper estilizado análisis. Si existiera algún impedimento para que ellos pudieran hablar y llegar a algún tipo de acuerdo voluntario, esa sería la situación final, con la persona $\mathrm{B}$ experimentando unos niveles de utilidad muy bajos debido a un nivel alto de humo (H1) en la habitación compartida.

Si los dos participantes no actuaran de esa manera tan miope, presunción de comportamiento bastante habitual en muchos manuales introductorios de economía maximizadora a la Robbins, sino que (modificando algunas de los supuestos implícitos en el análisis anterior) también estuvieran abiertos al diálogo y al intercambio, es razonable pensar que podrían alcanzar un acuerdo incluso únicamente pensando cada cual en su propio beneficio a corto plazo. Si partiéramos de la situación inicial S (a la que podría conducir $\mathrm{MI}_{1}$ y las otras presunciones incluidas en el análisis), la dirección y los términos de ese posible intercambio, es razonable pensar, exigirían que la persona no fumadora B tuviera que pagar al fumador para que éste fumara menos. ¿Cuánto tendría el no fumador que pagar al fumador por cada cigarrillo que éste dejara de fumar? Ciertamente dependería también de esos otros factores no considerados en este estilizado análisis. Por ejemplo, de la trayectoria de ambos y las circunstancias relacionales en las que se hubieran podido ver envueltos en el pasado reciente o de lo buenas personas que sean ambos debido a sus principios o normas éticas, morales o religiosas de comportamiento o de lo buenas personas que sean debido al mayor o menor grado en el que ambos incluyan el bienestar del otro como variable en la propia función de utilidad, por ejemplo. Por no mencionar 
otros muchos factores que podrían influir, como sus diferentes habilidades negociadoras o sus habilidades para hacer aliados fuera de la oficina.

Pero todo lo anterior, y mucho más, se encuentra deliberadamente incluido en el ceteris paribus del análisis gráfico aquí realizado. Es decir, se encuentra excluido de consideración para poder centrar la atención en los pocos aspectos que aquí se quieren resaltar. Recuérdese que la gráfica 2 constituye una revisión del clásico instrumental de la caja de Edgeworth-Bowley a efectos de poner énfasis en la dimensión distributiva asociada a la existencia de unos u otros marcos institucionales, así como a los impactos distributivos generados por las reformas institucionales.

$\mathrm{Y}$ en relación a ese posible intercambio que podría surgir a partir de la situación inicial S, la gráfica 2 muestra, en primer lugar, una hipotética situación intermedia en la que la fuerza negociadora de ambas partes fuera bastante similar o equilibrada, que ahora pasamos a detallar, pero también muestra otra hipotética situación con una fuerza negociadora desigual entre ambos agentes. El precio de un hipotético intercambio equilibrado, al que tal vez podrían llegar los participantes en el entorno institucional definido por el $\mathrm{MI}_{1}$ en vigor, vendría representado por $\mathrm{P}_{1}^{*}$. El fumador podría reducir el nivel de humo de $\mathrm{H} 1$ a $\mathrm{H} 2$ mientras que la persona no fumadora le transferiría una parte de su bien privado. Pero la posibilidad de un intercambio más desigual resulta incluso más probable que la anterior. Los términos del intercambio podrían ser, pues, más favorables para el fumador, quien está en una mejor posición negociadora dado el marco legal en vigor y los otros supuestos del análisis. $\mathrm{P}^{* *}$ reflejaría esa segunda posibilidad con un intercambio más desigual. El punto $S^{* *}$ vendría a representar la situación final tras dicho intercambio, donde el fumador acaba fumando más que en $S^{*}$ y obtiene una mayor cantidad del bien $X$.

Pero, ¿qué ocurriría si, de manera exógena para nuestro análisis, se produjera una reforma institucional mediante la que se prohibiera fumar? En nuestro simplificado análisis gráfico ello equivaldría a pasar de una situación con un marco institucional como el $\mathrm{MI}_{1}$ a otra con un marco institucional como el $\mathrm{MI}_{2}$ (prohibido fumar). Y ello significaría un cambio también drástico en materia de derechos y fuerza negociadora de las partes, dos de los aspectos básicos aquí considerados. En esa nueva, e igualmente estilizada situación, sería la persona no fumadora la que pasaría a tener el derecho inicial a decidir el nivel de humo en la sala. Y con las presunciones de nuestro análisis, lo normal es que eligiera un nivel cero de humo. El punto F representaría dicha nueva situación. 
El nivel de satisfacción o bienestar de ambos participantes cambiaría drásticamente respecto a lo que ocurría en la situación inicial creada por el anterior marco institucional (permitido fumar), como se refleja en las nuevas curvas de indiferencia en las que ambos aparecen situados tras la aprobación del nuevo marco institucional $\left(\mathrm{IA}_{1}, \mathrm{IB}_{2}\right)$. Si de nuevo relajásemos las presunciones del análisis general e hiciéramos factible la posibilidad de que los agentes pudieran de algún modo saltarse sin costo dicha prohibición, lo normal es que ahora tuviera que ser el fumador el que pagase al no fumador para que éste le dejara fumar algún cigarrillo a determinadas horas, a cambio de darle parte del bien $\mathrm{X}$ del que dispone, claro. La dirección de los flujos monetarios, o en especie, se vería así alterada también drásticamente por el simple hecho de que el marco institucional ha cambiado. ${ }^{19}$ De nuevo, si presupusiéramos un poder negociador similar, el precio del intercambio podría representarse como $\mathrm{P}_{2}^{*}$ y el posible resultado cabría representarlo gráficamente como el punto $\mathrm{F}^{*}$, situación comparativamente mejor para ambos participantes que la previamente reflejada en el punto F. Pero la reforma institucional suele alterar también, como ya se mencionó, la fuerza negociadora de las partes. Y en el nuevo entorno institucional y la nueva situación de partida creada, es la persona no fumadora la que tiene ahora mucha más fuerza negociadora que la fumadora, en comparación con la situación institucional anterior, por razones en las que no cabe extenderse aquí. El precio de ese intercambio más desigual y, en este caso, más favorable a los intereses del no fumador sería $\mathrm{P}_{2}^{*}$. La situación final, tras ese hipotético nuevo intercambio igualmente "voluntario", dadas las circunstancias institucionales y otras, vendría representado en nuestro análisis gráfico por el punto $F^{* *}$. Es decir, la persona fumadora lo haría hasta generar el nivel de humo reflejado en el punto $\mathrm{H} 6$ en lugar del representado por el punto H5, que resultaría de presuponer que ambos tuvieran un poder negociador equilibrado. Al fumador también le quedaría en este caso una cantidad menor del bien $X$ de la que resultaba de presuponer una negociación más equilibrada.

Obvio resulta afirmar que este nada heterodoxo instrumental gráfico, convenientemente modificado, permite mostrar de manera sencilla cómo la existencia de uno u otro marco institucional tiene relevantes consecuencias distributivas por-

${ }^{19}$ Aunque no se hace mención a la literatura relacionada, es evidente que éste es un ejemplo similar al clásico de la fábrica contaminante y el ayuntamiento que popularizó Ronald Coase. Pero, en nuestro caso, poniendo el énfasis en los impactos distributivos diferenciales que se derivan de la situación de partida. 
que ello afecta a los derechos y capacidades de decisión iniciales de los agentes. $\mathrm{Al}$ influir también sobre el poder negociador relativo de las personas participantes, tanto si éstas actúan en solitario como si lo hacen en equipo, es evidente que las reglas legales que conforman uno u otro mercado (marcos institucionales) influyen sin duda, junto a otros muchos factores claro, en los precios de los posibles intercambios "voluntarios" que tienen lugar bajo unos u otros de esos marcos institucionales existentes. "Voluntarios" dadas las circunstancias, claro. El estilizado análisis gráfico de estática comparativa aquí presentado tampoco permite adentrarnos en los asuntos relacionados con la acción colectiva o la acción política en equipo. Ni hemos resaltado apenas cómo pueden influir también los entramados de normas, valores, costumbres y hábitos sociales a los que hacemos referencia como marcos institucionales informales.

\section{Conclusiones}

Las argumentaciones y citas contenidas en el presente trabajo demuestran que aunque la preocupación por los aspectos relacionados con la eficiencia y los costos de transacción siguen siendo predominantes en los trabajos elaborados por los nuevos institucionalistas, varios y destacados autores están prestando cada vez más atención a la dimensión distributiva. Ese es el caso de los trabajos aquí mencionados. La ampliación de enfoque que ya tuvo lugar durante las décadas de 1980 y 1990, y que sirvió para distanciar dichas aportaciones respecto de los planteamientos neoclásicos tradicionales, se está viendo así ampliada también en la dirección de incorporar los aspectos distributivos.

Junto a lo anterior, la segunda aportación novedosa del presente trabajo ha consistido en realizar una modificación del instrumental gráfico de la caja de Edgeworth-Bowley a fin de mostrar de manera muy persuasiva y nada heterodoxa las vías por las cuales una reforma institucional genera importantes consecuencias distributivas, además de influir sobre los costos totales de transacción que soportan los agentes participantes en dicho entorno institucional. Como ha quedado resaltado en el trabajo, fue en el libro de Eggertsson (1990) donde por primera, y también última, vez se publicó hasta donde llega nuestra información una caja así reformada. Sin embargo, en su libro Eggertsson no utiliza dicha caja reformada para el mismo fin aquí perseguido, sino para enfatizar que los beneficios potenciales del intercambio de mercado voluntario podrían no 
hacerse efectivos si los costos de transacción fueran tan elevados como para hacer inviable el mismo.

Aquí se ha mostrado, en cambio, como las reglas que conforman un determinado marco institucional pueden hacer que unos agentes incurran en costos de transacción superiores a los que se derivarían de su no existencia (e incluso a pagar como consecuencia un precio superior), mientras que otros encuentren en dichas reglas el mecanismo que les permite exigir y obtener, al menos a corto plazo, unos mayores ingresos o rentas, incluso compensándoles de los mayores costos de transacción en los que hayan de incurrir como resultado de la necesaria negociación, en su caso. Obvio resulta concluir también que la acción política orientada a reformar esos marcos institucionales suele estar muy influida por los impactos distributivos que cada grupo de participantes espera de unas y otras reformas alternativas.

Una modificación en la legislación laboral, por ejemplo, a fin de introducir distintas modalidades de contratación temporal allí donde no existan podrá permitir, sin duda, una mayor flexibilidad organizativa en el ámbito de la organización empresarial, por ejemplo, disminuyendo los costos de transacción asociados a la reorganización del trabajo, el despido, la negociación de retribuciones, etcétera, pero ello tiene consecuencias muy distintas en términos distributivos para unos y otros de los participantes directamente afectados por la reforma. Los cambios o reformas institucionales afectan a los derechos, las capacidades de decisión y la fuerza negociadora relativa de las partes.

Aunque los costos de transacción totales resultasen disminuidos por una determinada reforma institucional, ello no garantiza que no haya participantes que resulten distributivamente afectados en un sentido negativo. Por lo que cabe esperar que las mejoras de eficiencia sean más defendidas por aquellos que esperan salir ganando con las mismas, en uno u otro aspecto, que por quienes esperan salir perjudicados, oponiéndose éstos a las mismas o tratando de reorientarlas hacia direcciones más favorables, con mayor o menor determinación dependiendo, entre otros factores, de los conocidos costos asociados a la acción colectiva que en el presente análisis gráfico no han sido considerados.

Todas estas consideraciones distributivas que ya están ganando más y más espacio en las aportaciones de los nuevos institucionalistas son, por otra parte, aspectos habitualmente tratados en las publicaciones surgidas de otras corrientes de análisis, tanto económico como político. El objetivo del presente trabajo no ha sido el indagar en estas otras contribuciones, sino el mostrar, primero, que 
estos aspectos ya están presentes también en el campo de la nueva economía institucional y, segundo, que estas ideas y razonamientos tradicionalmente tenidos por heterodoxos pueden ser explicados de manera muy persuasiva mediante un instrumental gráfico nada heterodoxo, eso sí, una vez reformado convenientemente.

Como el poder de las ideas no es independiente de la manera en la que los razonamientos se construyen y expresan, se sostiene que la modificación aquí utilizada de ese instrumental gráfico (popularizado por Wilfredo Federico Damaso Pareto y Arthur Lyon Bowley a partir de las contribuciones pioneras de Ysidro Edgewroth hace ya más de cien años) es un tema de la máxima importancia. Así lo creen también los alumnos del curso de doctorado sobre instituciones y comportamiento económico que, junto a otros colegas, he venido impartiendo durante los últimos años. Clarísima les queda la idea de que "las instituciones influyen también sobre la distribución, no sólo sobre la eficiencia." Sirva esta última cita que sigue, nada reciente por otra parte, para volver a remarcar que cada vez más nuevos institucionalistas están prestando atención a estos aspectos. Libecap (1993: 32) afirmaba ya a principios de la década de 1990, en este sentido, lo siguiente: "Estos aspectos influyen sobre los incentivos de cada una de las partes negociadoras en un proceso de cambio institucional y, por lo tanto, sobre el resultado de la negociación. La distribución de la riqueza y el reparto del poder político suelen estar siempre en juego. Y lo normal es que la reforma conlleve la aparición de ganadores y perdedores".

\section{REFERENCIAS}

Alston, L.J., Eggertsson, Th. y North, D.C. (eds.), 1996. Empirical Studies in Institutional Change. Cambridge: Cambridge University Press.

Bardhan, P.K, 2000. Understanding Underdevelopment. Challenges for Institutional Economics From the Point of View of Poor Countries. Journal of Institutional and Theoretical Economics, 156, pp. 216-35. [Re-editado en: C. Ménard (ed.), 2004. The International Library of New Institutional Economics (Vol. VI). Cheltenham: Edward Elgar Publishing].

Bardhan, P., 2001. Distributive Conflicts, Collective Action, and Institutional Economics. En: G.M. Meier y J.E. Stiglitz. Frontiers of Development Economics: The Future in Perspective. Oxford: Oxford University Press.

Bardhan, P., 2004. Scarcity, Conflicts, and Cooperation. Essays in Institutional and Political Economy of Development. Cambridge: The MIT Press. 
Bardhan, P., 2005. Institutions Matter, But Which Ones? The Economics of Transition, 13(3), pp. 499-532.

Caballero, G., 2006. The Industrial Organization of Congress in UsA and Spain: A comparative institutional analysis. Revista de Análisis Económico, 21(2), pp. 105-23.

Caballero, G., 2011. Institutional Foundations, Committee System and Amateur Legislators in the overnance of the Spanish Congress: An institutional comparative perspective (USA, Argentina, Spain). En: N. Schofield y G. Caballero (eds.). Political Economy of Institutions, Democracy and Voting. Berlín: Springer.

Caballero, G. y Kingston, C., 2005. Capital social e instituciones en el proceso de cambio económico. Ekonomiaz, 59, pp. 72-93.

Eggertsson, Th., 1990. Economic Behaviour and Institutions. Cambridge: Cambridge University Press.

Eggertsson, Th., 1995. Economic Perspectives on Property Rights and the Economics of Institutions. En: P. Foss. Economic Approaches to Organizations and Instituions (pp. 4761). Aldershot: Dartmouth Publishing Company Ltd.

Eggertsson, Th., 1996. A Note on the Economics of Institutions. En: L.J. Alston, Th. Eggertsson y D.C. North (eds.). Empirical Studies in Institutional Change. Cambridge: Cambridge University Press.

Eggertsson, Th., 2005. Imperfect Institutions. Opportunities and Limits of Reform. Ann Arbor, MI: University of Michigan Press.

Greif, A., 2005. Commitment, Coercion, and Markets: The nature and dynamics of institutions supporting exchange. En: C. Ménard y M.M. Shirley (eds.). Handbook of New Institutional Economics. Dordrecht: Springer.

Greif, A., 2008. Toward Political Economy of Implementation: The Impact of administrative power on institutional and economic developments. En: E. Helpman (ed.). Institutions and Growth. Cambridge, MA: Harvard University Press.

Harris, J., Hunter, J. y Lewis, L. 1995. The New Institutional Economics and Third World Development. Londres: Routlege.

Hodgson, G., 1989. Institutional Economic Theory: The Old versus the New. Review of Political Economy, 1(3), pp. 249-69.

Hodgson, G., 1993. Institutional Economics. Surveying the Old and the New. Metroeconomica, 44(1), pp. 27-54.

Hodgson, G., 1998. The Approach of Institutional Economics. Journal of Economic Literature, 36, pp. 166-92.

Horn, M.J., 1995. The Political Economy of Public Administration. Institutional Choice in the Public Sector. Cambridge, MA: Cambridge University Press.

Hutchison, T.W., 1984. Institutional Economics: Old and New. Journal of Institutional and Theoretical Economics, 140(1), pp. 20-33. 
Kahnerman, D., 1994. New Challenges to the Rationality Assumption. Journal of Institutional and Theretical Economics, 150(1), pp. 18-36.

Knight, J., 1992. Institutions and Social Conflict (The Political Economy of Institutions and Decisions Series) Cambridge: Cambridge University Press.

Knight, J. y North, D.C., 1997. Explaining the Complexity of Institutional Change. En: D. Waimer (ed.). Organizational, and Structural Changes in Industries and Firms. Norwell, MA: Kluwer Academic Publishers.

Knudsen, Ch., 1993. Modelling Rationality, Institutions and Processes in Economic Theory. En: U. Maki, B. Gustafsson y Ch. Knudsen (eds.). Rationality, Institutions and Economic Methodology (pp. 265-99). Londres: Routledge University Press.

Langlois, R.N., 1990. Bounded Rationality and Behavioralism: A Clarification and Critique. Journal of Instititutional and Teoretical Economics, 146(4), diciembre, pp. 691-95.

Libecap, G.D, 1989a. Distributional Issues in Contracting for Property Rights. Journal of Institutional and Theoretical Economics, 145, pp. 6-24.

Libecap, G.D., 1989b. Contracting for Property Rights. Cambridge: Cambridge University Press.

Libecap, G.D., 1993. Politics, Institutions, and Institutional Change. Comment. Journal of Institituional and Teoretical Economics, 149(1), pp. 29-35.

Ménard, C., 1997. Internal Characteristics of Formal Organizations. En: C. Pitelis et al. Transaction Costs Economics: Recent Developments. Cheltenham: Edward Elgar Publishing.

Ménard, C. (ed.), 2004. The International Library of the New Institutional Economics (7 volúmenes). Cheltenham: Edward Elgar Publishing.

Ménard C. y Shirley, M.M. (eds.), 2005. Handbook of New Institutional Economics. Cheltenham: Edward Elgar Publishing.

Mokyr, J. y Nye, J.V.C., 2007. Distribution Coalitions, the Industrial Revolution, and the Origins of Economics Growth in Britain. Southern Economic Journal, 74(1), julio, pp. 50-70.

Nye, J.V., 1997. Thinking about the State: Property rights, trade, and changing contractual arrangements in a world with coercion. En: J.N. Drobak y J. Nye (eds.). The Frontiers of the New Institutional Economics (pp. 121-44). San Diego: Academic Press.

North, D.C., 1990. Institutions, Institutional Change, and Economic Performance. Cambridge: Cambridge University Press.

North, D.C., 2005a. Understanding the Process of Institutional Change. Princeton: Princeton University Press.

North, D.C., 2005b. Institutions And the Performance of Economies Over Time. En: C. Ménard y M. Shirley (eds.). Handbook of New Institutional Economics (pp. 1-16). Cheltenham: Edward Elgar Publishing.

North, D.C. y Weingast, B.R., 1989. Constitutions and Commitment: The Evolution of Institutions Governing Public Choice in Seventeenth-Century England. Journal of Economic History, XLIX(4), pp. 803-32. 
Ostrom, E., 2005. Understanding Institutional Diversity. New Jersey: Princeton University Press.

Ostrom, E., 2007a. A Diagnostic Approach For Going Beyond Panaceas [en línea]. Proceedings of the National Academy of Sciences, 104(39), septiembre, pp. 15181-7. Disponible en: < http://www.pnas.org/content/104/39/15181.full.pdf + html $>$.

Ostrom, E., 2007b. Challenges and Growth: The development of the interdisciplinary field of institutional analysis. Journal of Institutional Economics, 3(3), pp. 239-64.

Ostrom, E. y Ahn, T.K, 2008. The Meaning of Social Capital and its Link to Collective Action. En: G.T. Svendsen y G.L. Svendsen (eds.). Handbook on Social Capital. Northampton, MA: Edward Elgar Publishing.

Ostrom, E. y Walker, J. (eds.), 2005. Trust and Reciprocity. Nueva York: Russell Sage Foundation.

Pagano, U., 2007. Bounded Rationality and Institutionalism. En: G. Hodgson (ed.). The Evolution of Economic Institutions (pp. 19-33). Northampton, MA: Edward Elgar Publishing.

Poteete, A.R., Janssen, M.A. y Ostrom, E., 2010. Working Together. New Jersey:Princeton University Press.

Rutherford, M., 1994. Institutions in Economics. Cambridge: Cambridge University Press.

Rutherford, M., 1995. The Old and the New Institutionalism: Can bridges be built? Journal of Economic Issues, 29(2), junio, pp. 443-51.

Selten, R., 1990. Bounded Rationality. Journal of Institutional and Theoretical Economics, 146(1), pp. 649-58.

Simon, H.A., 1976. From Substantive to Procedural Rationality. En: S.J. Latsis. Method and Appraisal in Economics. Cambridge: Cambridge University Press.

Simon, H.A., 1978. Rationality as Process and as Product of Thought. The American Economic Review, 68(2), mayo, pp. 27-56.

Simon, H.A., 1979. Rational Decision Making in Business Organization. The American Economic Review, 69(4), septiembre, pp. 493-513.

Svendsen G.T. y Svendsen, G.L. (eds.), 2008. Handbook on Social Capital. Northampton, MA: Edward Elgar Publishing.

Toboso, F., 1995. Explaining the Process of Change Taking Place in Legal Rules and Social Norms: The cases of Institutional Economics and New Institutional Economics. European Journal of Law and Economics, 2(1), pp. 63-84.

Toboso, F., 1997. ¿En qué se diferencian los enfoques de la vieja y la nueva economía institucional? Hacienda Publica Española, 143(4), pp. 175-92.

Toboso, F., 2001. Institutional Individualism and Institutional Change: The search for a middle way mode of explanation. Cambridge Journal of Economics, 25(6), noviembre, pp. $765-83$. 
Toboso, F., 2013. Methodological Developments in the Old and New Institutional Economics. History of Economic Ideas, 1, enero-marzo, pp. 77-116.

Toboso, F. y Arias, X.C. (eds.), 2006. Organización de gobiernos y mercados. Análisis de casos desde la nueva economía institucional. España: Publicacions Universitat de ValènciaUniversidad de Vigo.

Toboso, F. y Compés, R., 2003. Nuevas tendencias analíticas en el ámbito de la Nueva Economía Institucional. La incorporación de los aspectos distributivos. El Trimestre Económico, LXX(4)(280), octubre-diciembre, pp. 637-71.

Tsebelis, G., 1990. Nested Games. Berkeley: University of California Press.

Tsebelis, G. 2002. Veto Players: How political institutions work. Nueva York: Princeton University Press-Russell Sage Foundation.

Weingast, B.R., 1989. The Political Institutions of Representative Government Legislatures. Journal of Institutional and Theretical Economics, 145, pp. 693-703.

Weingast, B.R. y Marshall, W.J., 1988. The Industrial Organization of Congress. Or Why Legislatures like Firms Are Not Organized as Markets. Journal of Political Economy, 96(1), pp. 132-63.

Williamson, O.E., 1990. A Comparison of Alternative Approaches to Economic Organization. Journal of Institutional and Theoretical Economics, 146(1), pp. 61-71. Williamson, O.E., 1996a. Efficiency, Power, Authority and Economic Organization. En: J. Groenewegen. Transaction Cost Economics and Beyon. Masssachusetts: Kluwer Academic Press.

Williamson, O.E., 1996b. The Politics and Economics of Redistribution and Efficiency. En: O.E. Williamson. The Mechanisms of Governance. Oxford: Oxford University Press.

Williamson, O.E., 1996c. The Institutions and Governance of Economic Development and Reform. En: O.E. Williamson. The Mechanisms of Governance. Oxford: Oxford University Press.

Williamson, O.E., 1997. Hierarchies, Markets and Power in the Economy: An economic perspective. En: C. Ménard (ed.). Transaction Cost Economics. Recent Developments. Northampton, MA: Edward Elgar Publishing.

Williamson, O.E., 2000. The New Institutional Economics: Taking Stock, Looking Ahead. Journal of Economic Literature, 38, septiembre, pp. 595-613.

Williamson, O.E. 2002a. The Theory of the Firm as a Governance Structure: From Choice to Contract. The Journal of Economic Perspectives, 168(3), pp. 171-95.

Williamson, O.E. 2002b. The Lenses of Contract: Private Ordering. The American Economic Review, 92(2), pp. 438-43.

Williamson, O.E., 2003. Examining Economic Organization Through the Lens of Contract. Industrial and Corporate Change, 12, pp. 917-42. 
Winiecki, J., 1986. Soviet-type Economies: Considerations for the future. Soviet Studies, 10, pp. 543-61.

Winiecki, J., 1991. On Inevitability of Output Fall in Early Transition to the Market: Theoretical Underpinnings. Soviet Studies, 4, pp. 119-36.

Winiecki, J., 1993. The Political Economy of Big-Bang: Free market versus New Keynesian perspectives. Banca Nationale del Lavoro Quaterly Review, 187, pp. 407-28.

Winiecki, J., 1994. Shaping the Institutional Infrastructure. Economic Inquiry, 32, enero, pp. 66-78.

Winiecki, J., 1996. Why Economic Reforms fail in the Soviet System: A Property rightsbased approach. En: L.J. Alston, Th. Eggertsson y D.C. North (eds.). Empirical Studies in Institutional Chang. Cambridge: Cambridge University Press.

Winiecki, J., 1998. Formal and Informal Rules in Post-Communist Transition. Journal of Public Finance and Public Choice, 16(1), pp. 3-26. 